\title{
Die Matrix
}

Liebe Leserin, lieber Leser,

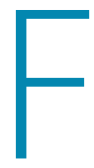

asern als verstärkendes Element im Kunststoffbauteil sind Gegenstand zahlreicher Untersuchungen. Sie können ihre Eigenschaften aber nur ausspielen, wenn ihre Einbettung in die Kunststoffmatrix und das Polymer selbst genau aufeinander abgestimmt sind. Damit wird klar, welche Bedeutung die eingesetzten Duro- oder Thermoplaste für den gesamten Verbund haben. Während zu Beginn der Herstellung meist glasfaserverstärkter Kunststoffe die langen Aushärtezeiten nach dem Handlaminieren mehr oder weniger hingenommen wurden, wird heute immer größeres Augenmerk auf möglichst kurze Zykluszeiten im Serienprozess gelegt. Und damit rückt die Kunststoffeinbettung der Faser in den Fokus von Forschung und Entwicklung.

Die Anforderungen an den Matrixwerkstoff sind nicht gering. Gewünscht sind Systeme, die eine zügige Faserimprägnierung, schnelle Aushärtung, qualitativ gleichmäßige sowie kostengünstige Produktion erlauben und Bauteile hervorbringen, die neben den gewünschten mechanischen Kennwerten möglichst wenig nachbearbeitet werden müssen, eine hohe Oberflächenqualität aufweisen und im idealen Fall gut rezyklierbar sind. Zudem muss die Matrix an Stellen, wo Bauteile geklebt werden, die gesamte Kraft übertragen, da hier ja der Faserverlauf unterbrochen ist.

Die Entwicklung hat bislang sehr Vielversprechendes hervorgebracht. Seit es mit Zusatzstoffen möglich ist, eine schlagartige Aushärtung zeitlich so zu steuern, dass vorher eine niedrigviskose und damit druckärmere Imprägnierung erfolgt, sind im RTM-Prozess fast schon Produktionszyklen möglich, wie sie in der Automobilindustrie gefordert sind. Bei den sogenannten Direktverfahren lassen sich Bauteile auch direkt zum Beispiel aus Glasfasern, Polymeren und Additiven im Fließpressverfahren formen. Und reaktive Matrizes vereinen bereits die Vorteile von Duroplasten mit denen von Thermoplasten, wobei allerdings eine Serienreife noch nicht in Sicht ist.

Um Ihnen einen Gesamteindruck zu dieser Thematik zu geben, beschreiben die Autoren des Instituts für Verbundwerkstoffe in Kaiserslautern im Beitrag "Potenziale neuer Matrixpolymere für die FKV-Bauteilfertigung" den Stand der Technik und zeigen Trends und Zukunftspotenzial und Neuentwicklungen der Matrixkunststoffe auf. Auch die weiteren Beiträge werden Sie bei Ihrer Arbeit unterstützen. Eine erhellende Lektüre wünscht

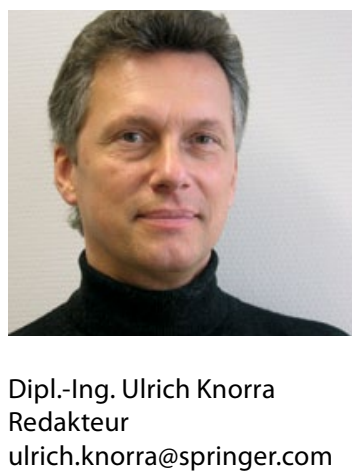

